\title{
Opener für kleineren Kanaleingang
}

Den Opener OP10L19.204.030 aus Nickel-Titan gibt es nun auch mit kleinerem Taper (.08) und Durchmesser (025) als OP08L19.204.025. Damit ist er ein Spezialist für die Zahnärzte, die den Kanaleingang etwas kleiner gestalten möchten. Im koronalen Drittel eingesetzt, kommen alle Vorteile zum Tragen: Er befreit den Kanal bereits zu Anfang der Behandlung zuverlässig vom Großteil der Bakterien. Durch seinen Doppel-SQuerschnitt zeigt das kurze Instrument eine angenehme Flexibilität, schützt vor Überpräparation und sorgt für einen schnellen und gründlichen $\mathrm{Ab}$ trag von koronal infiziertem Gewebe. Der Behandler erhält ein besseres Sichtfeld, insbesondere in Kombination mit einem Mikroskop bzw. einer Lupenbrille. Außerdem entlastet der Opener alle nachfolgenden Feilen wie z.B. die primäre Sondierung per Handfeile (z.B. K-Feile in Größe 010) und die anschließende Gleitpfaderstellung per PathGlider (in Größe 015 oder 020).

Nach einer Pressemitteilung der

Komet Dental Gebr. Brasseler GmbH \& Co KG,

Lemgo

www.kometdental.de



